\section{Lactobacillus Acidophilus and Lactobacillus Casei Exposed to Wi- Fi Radiofrequency Electromagnetic Radiation Show Enhanced Growth and Lactic Acid Production}

\author{
Amanat S. ${ }^{1 \oplus}$, Mazloomi S. M. ${ }^{2}$, Asadimehr H. ${ }^{3}$, Sadeghi F. ${ }^{4}$, \\ Shekouhi F. ${ }^{5}$, Mortazavi S. M. J.
}

\begin{abstract}
Background: Lactobacillus acidophilus and Lactobacillus casei are gram-positive probiotics and members of the genus Lactobacillus. These bacteria are widely applicable in food and dairy industries. Increasing bacterial load and decreasing fermentation time make them more profitable for manufacturers.

Objective: This study was aimed at assessing the biological effects of short-term exposure of $L$. acidophilus and $L$. casei to $2.4 \mathrm{GHz}$ Wi-Fi radiofrequency electromagnetic fields (RF-EMF) generated by a Wi-Fi router on the lactic acid production and proliferation of these probiotic bacteria.
\end{abstract}

Material and Methods: This experimental study was performed on pure culture strains of $L$. acidophilus and $L$. casei, first direct vat sets (DVS) were activated in MRS broth for 24 hours then transferred to new culture mediums. Afterward, these mediums were exposed to RF-EMF for 15, 30, 45 and 60 minutes. The control samples were sham-exposed. After 72 hours of incubation on MRS agar cell counts were enumerated.

Results: Exposure for 30, 45 and 60 minutes significantly increased the growth of $L$. acidophilus and L. casei. No difference was found between the growth of the samples exposed to RF-EMF for 15 minutes compared to that of sham-exposed bacteria. In addition, lactic acid concentration in L. acidophilus medium was amplified after 15,30 and 45 minutes of exposure. However, in $L$. casei samples, only 30 and 60 min exposures could stimulate the production of lactic acid.

Conclusion: L. acidophilus and L. casei probiotic bacteria exposed for a short time to radiofrequency electromagnetic radiation (RF-EMF) generated by a widely used commercial Wi-Fi router show significantly increased proliferation and lactic acid production.

Citation: Amanat S, Mazloomi SM, Asadimehr H, Sadeghi F, Shekouhi F, Mortazavi SMJ. Lactobacillus Acidophilus and Lactobacillus Casei Exposed to Wi-Fi Radiofrequency Electromagnetic Radiation Show Enhanced Growth and Lactic Acid Production. J Biomed Phys Eng. 2020;10(6):745-750. doi: 10.31661/jbpe.v0i0.1056.

Keywords

Radiation; Electromagnetic; Probiotics; Lactobacillus acidophilus; Lactobacillus Casei

\section{Introduction}

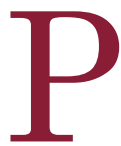

robiotics, a Greek term meaning "for life", can be defined as microorganisms that provide specific health advantages for the host when administered in adequate amounts [1]. As a major limita-
${ }^{1} \mathrm{MSc}$, Student Research Committee, Larestan

University of Medical Sci

ences, Larestan, Iran

${ }^{2} \mathrm{PhD}$, Nutrition Research

Center, Shiraz University

of Medical Sciences,

Shiraz, Iran

${ }^{3} \mathrm{BSc}$, Department of

Clinical Nutrition, Schoo

of Nutrition \& Food Sci-

ences, Shiraz University

of Medical Sciences,

Shiraz, Iran

${ }^{4} \mathrm{MSc}$, Department of

Clinical Nutrition, School

of Nutrition \& Food Sci-

ences, Shiraz University

of Medical Sciences,

Shiraz, Iran

${ }^{5} \mathrm{MSc}$, Department of

Medical Physics, Shiraz

University of Medical Sci-

ences, Shiraz, Iran

${ }^{6} \mathrm{PhD}$, Department of

Medical Physics, Shiraz

University of Medical Sci-

ences, Shiraz, Iran

${ }^{7} \mathrm{PhD}$, lonizing and Non-

ionizing Radiation Pro-

tection Research Center,

School of Paramedical

Sciences, Shiraz Univer-

sity of Medical Sciences,

Iran

*Corresponding author:

S. M. J. Mortazavi

Department of Medical

Physics, Shiraz Univer-

sity of Medical Sciences,

Shiraz, Iran

E-mail: mortazavismj@

gmail.com

Received: 1 December 2018

Accepted: 10 February 2019 
tion, products containing probiotic bacteria must contain $>10^{7}$ living microorganisms/ gram. Over the last decade, an enormous number of studies have observed beneficial effects of probiotics supplements and foods containing these bacteria on a vast spectrum of disease; from immune function and infection to gastrointestinal disorders and metabolic diseases [2-4]. It is believed that one of the potential health benefits of these bacteria is due to lactic acid production. Lactic acid decreases the level of $\mathrm{pH}$ in the digestive system and precludes the detrimental bacteria growth [5]. Moreover, fermentation process of probiotics and its byproducts like lactic acid is highly desirable for food and chemical industries. Therefore, they apply well-known approaches such as temperature regulation and oxygen exposure to accelerate bacterial reproduction and fermentation.

Non-ionizing electromagnetic radiation at frequencies ranging $300 \mathrm{MHz}$ to $300 \mathrm{GHz}$ are known as microwaves. Microwaves are widely used in mobile phones, Wi-Fi, radars, etc. Over the past several years, studies have shown microwave irradiation can alter microorganism subcellular metabolism. Some studies have shown that microwave exposure can decrease the growth of pathogen bacteria and stop urease activity [6]. Kushwah et al., showed that exposing Bacillus subtitles to low power microwave resulted in amylase and pectinase activity alteration along with an increase in exopolysaccharide production [7]. Depending on radiation period and intensity, microwave may either stimulate or suppress the fungal growth $[8,9]$. These results indicate that only if microorganisms are treated with microwave exposure at right frequency and duration, desirable changes in growth and metabolism would be induced.

Lactobacillus acidophilus and Lactobacillus casei are gram-positive probiotics which belong to the genus Lactobacillus. These bacteria are widely applicable in food and dairy industries. Increasing bacterial load and decreasing fermentation time make these industries more profitable. Therefore, this study was aimed at assessing the biological effects of short-term exposures of L. acidophilus and L. casei probiotic bacteria to $2.4 \mathrm{GHz}$ RF-EMF generated by a commercial Wi-Fi router on the lactic acid production and proliferation and of these microorganisms.

\section{Material and Methods}

In this experimental study, pure culture strains of L. acidophilus and L. casei (DVS, Chris- Hansen Denmark) were cultured in MRS broth medium (Merck, Darmstadt, Germany) at $37{ }^{\circ} \mathrm{C}$ for 18 hours. Then $500 \mu \mathrm{L}$ of the mixed suspension was transferred to MRS broth again and incubated at $37^{\circ} \mathrm{C}$ for 6 hours. After incubation, samples were exposed to the RF-EMF emitted from a $2.4 \mathrm{GHz}$ Wi-Fi router (D-Link, D-Link Corporation, Taiwan) for 15, 30,45 and 60 minutes at the distance of $5 \mathrm{~cm}$ from the router antenna. The control samples were sham-exposed to RF-EMF. The specific absorption rate (SAR) level was computed by an expert. After exposure, mixed suspensions were diluted up to $10^{-6}$ and $100 \mu \mathrm{L}$ of diluted samples was transferred to the MRS agar medium (Merck, Darmstadt, Germany) and incubated for 72 hours at $37{ }^{\circ} \mathrm{C}$ in an anaerobic jar (AnaerocultA gas pack, MerckDarmstadt, Germany). Bacterial counts were enumerated after 72 hours of incubation. These counts were reported as colony forming unit (CFU) per ml. After 6 hours of incubation at $37^{\circ} \mathrm{C}, 1$ $\mathrm{ml}$ of each suspension was used for the lactic acid assay.

\section{Lactic acid measurement}

In order to estimate the level of lactic acid, Kimberley and Taylor's method was used [10] with some modifications. The medium was centrifuged (Sigma 3K30, Germany) at 7500 $\mathrm{rpm}$ for $15 \mathrm{~min}$. One $\mathrm{ml}$ of the supernatant after ten-fold dilution was added to $1 \mathrm{ml}$ of $20 \%$ $\mathrm{CuSO}_{4}$ (Merck, Darmstadt, Germany) solution followed by $8 \mathrm{ml}$ water and $1 \mathrm{~g}$ calcium 
Wi-Fi Radiation Effects on Probiotic Bacteria

hydroxide. After 30 minutes rest at room temperature, the mixture was centrifuged for 15 $\mathrm{min}$ at $7500 \mathrm{rpm}$. One $\mathrm{ml}$ of remaining liquid was added to $0.05 \mathrm{ml}$ of $4 \% \mathrm{CuSO}_{4}$ solution and after that $6 \mathrm{ml}$ concentrated sulfuric acid was added to the mixture (Merck, Darmstadt, Germany). After complete mixing on a vortex mixer for $5 \mathrm{~min}$, the solution was incubated in boiling water for $5 \mathrm{~min}$ followed by a cooling bath phase. Next step was adding $0.1 \mathrm{ml}$ of $1.5 \%$ p-hydroxydiphenyl (Sigma, Germany) dissolved in 95\% ethanol and 30 min incubation at room temperature. The mixture was then placed in boiling water bath for $90 \mathrm{sec}$ onds. After cooling, absorbance was read at $410 \mathrm{~nm}$ (Apel PD303, Japan). Then the same method was used to obtain a standard curve for pure lactic acid (Sigma, Germany) and lactic acid concentration of the samples was measured.

\section{Statistical analysis}

The means and standard deviation (SD) were compared using the non-parametric MannWhitney test and comparison between groups were done by using Kruskal-Wallis test. Data were log-transformed and effect of radiation on lactic acid concentration was assessed by ANCOVA with a number of CFU as the covariate. $\mathrm{P}<0.05$ was considered as statistically significant.
Results

The growth of $L$. acidophilus after exposure to RF-EMF for 30, 45 and $60 \mathrm{~min}$ significantly increased $(\mathrm{P}<0.01, \mathrm{P}<0.01, \mathrm{P}<0.01$, respectively) compared to bacteria received a sham-exposure. Moreover, no difference was found between the growth of samples exposed to RF-EMF for $15 \mathrm{~min}$ and bacteria that were sham-exposed (Table 1). In a similar pattern, while no difference was observed between the growth of samples exposed to RF-EMF for $15 \mathrm{~min}$, the L. casei proliferation in samples irradiated for 30,45 and 60 minutes significantly increased $(\mathrm{P}<0.05, \mathrm{P}<0.01$ and $\mathrm{P}<0.01$, respectively) compared to bacteria that were sham-exposed (Table 1).

After exposure to RF-EMF for 15, 30 and 45 min, lactic acid concentrations in the medium of L. acidophilus were significantly higher than the shame-exposed bacteria $(\mathrm{P}=0.003$, $\mathrm{P}=0.002$, and $\mathrm{P}=0.001$, respectively). Moreover, the difference between these three groups was not statistically significant $(\mathrm{P} \geq 0.05)$ (Table 2). The concentration of lactic acid in $L$. casei mediums were significantly higher after 30 and $60 \mathrm{~min}$ exposure to RF-EMF $(\mathrm{P}=0.006$ and $\mathrm{P}=0.004$, respectively). Though, 15 and $45 \mathrm{~min}$ exposure to RF-EMF failed to increase lactic acid levels significantly $(\mathrm{P} \geq 0.05)$ (Table 2). Independent effect of RF radiation on a lactic acid production of $L$. acidophilus

Table 1: Colony forming unit (per $\mathrm{ml} \times 10^{5}$ ) in the control samples and those exposed for 15,30 , 45 and $60 \mathrm{~min}$ to $2.4 \mathrm{GHz}$ Wi-Fi radiofrequency radiation.

L. acidophilus CFU (mean \pm S.D)

\section{L. casei CFU (mean \pm S.D)}

\begin{tabular}{ccccccc}
\hline Exp. Time & $\begin{array}{c}\text { Sham- } \\
\text { exposed }\end{array}$ & $\begin{array}{c}\text { RF-EMF } \\
\text { Exposure }\end{array}$ & *p-value & $\begin{array}{c}\text { Sham- } \\
\text { exposed }\end{array}$ & $\begin{array}{c}\text { RF-EMF } \\
\text { Exposure }\end{array}$ & *p-value \\
\hline $\mathbf{1 5} \mathbf{~} \mathbf{m i n}$ & $8.25 \pm 0.41$ & $8.48 \pm 0.11$ & 0.151 & $7.40 \pm 0.80$ & $8.07 \pm 0.40$ & 0.097 \\
\hline $\mathbf{3 0} \mathbf{~}$ in & $7.48 \pm 0.26$ & $8.15 \pm 0.15$ & 0.001 & $7.34 \pm 0.66$ & $8.11 \pm 0.48$ & 0.041 \\
\hline $\mathbf{4 5} \mathbf{~}$ in & $7.69 \pm 0.30$ & $8.62 \pm 0.15$ & 0.002 & $7.5 \pm 0.53$ & $8.46 \pm 0.41$ & 0.008 \\
\hline $\mathbf{6 0} \mathbf{~}$ in & $7.55 \pm 0.20$ & $8.67 \pm 0.09$ & 0.002 & $7.57 \pm 0.48$ & $8.80 \pm 0.09$ & 0.002
\end{tabular}

*Mann-Whitney test 
Amanat S., Mazloomi S, M., Asadimehr H. et al

Table 2: Effect of low power microwaves (MW) on lactic acid production in L. acidophilus and L. casei

L. acidophilus

\begin{tabular}{|c|c|c|c|c|}
\hline $\begin{array}{l}\text { Duration of RF- } \\
\text { EMF Exposure } \\
\text { (min) }\end{array}$ & $\begin{array}{l}\text { Lactic acid }(\mu \mathrm{g} / \\
\mathrm{ml}) \text { (Mean } \pm \mathrm{SD})\end{array}$ & $\begin{array}{l}\text { Magnitude of the } \\
\text { change (compared } \\
\text { to sham) (\%) }\end{array}$ & $\begin{array}{l}\text { Lactic acid }(\mu \mathrm{g} / \\
\mathrm{ml})(\text { Mean } \pm \mathrm{SD})\end{array}$ & $\begin{array}{l}\text { Magnitude of the } \\
\text { change (compared } \\
\text { to sham) (\%) }\end{array}$ \\
\hline Sham (0 min) & $291.12 \pm 16.88$ & 0.00 & $176.37 \pm 12.74$ & 0.00 \\
\hline 15 & $352.97 \pm 9.87$ & *21.24 & $210.46 \pm 24.59$ & 19.32 \\
\hline 30 & $359.12 \pm 43.69$ & *23.35 & $229.51 \pm 33.43$ & *30.12 \\
\hline 45 & $359.42 \pm 16.76$ & **23.46 & $174.53 \pm 44.02$ & -1.04 \\
\hline 60 & $332.40 \pm 30.36$ & 14.17 & $231.04 \pm 26.49$ & *30.99 \\
\hline
\end{tabular}

$\mathrm{P}$-value compared to those of the sham-exposed group, $* \mathrm{P}<0.05 ; * * \mathrm{P}<0.001$.

and $L$. case $i$ were confirmed by ANCOVA test $(\mathrm{P}<0.001$ and $\mathrm{P}=0.012$ respectively $)$. Alterations of lactic acid production in L. acidophilus and L. casei exposed to $2.4 \mathrm{GHz}$ Wi-Fi radiofrequency radiation for 15, 30, 45 and 60 min are shown in Figure 1.

\section{Discussion}

Altogether, the findings of present study revealed that both Lactobacillus acidophilus and Lactobacillus casei exposed to $2.4 \mathrm{GHz}$ RF-EMF produced by a commercial Wi-Fi router showed significantly increased lactic acid production and proliferation. Using RFEMFs to alter the growth of various fungi and bacteria have been studied before. However, these studies showed different results based on species and intervention traits [11-13]. In this light, Kushwah et al., reported while 2 min exposure to $2450 \mathrm{MHz} \mathrm{MW}$ radiation enhanced Streptococcus mutans growth, four minutes of the same exposure reduced the growth of Pectobacteriumcarotovorum [7]. Even in the same species, e.g. Saccharomyce-

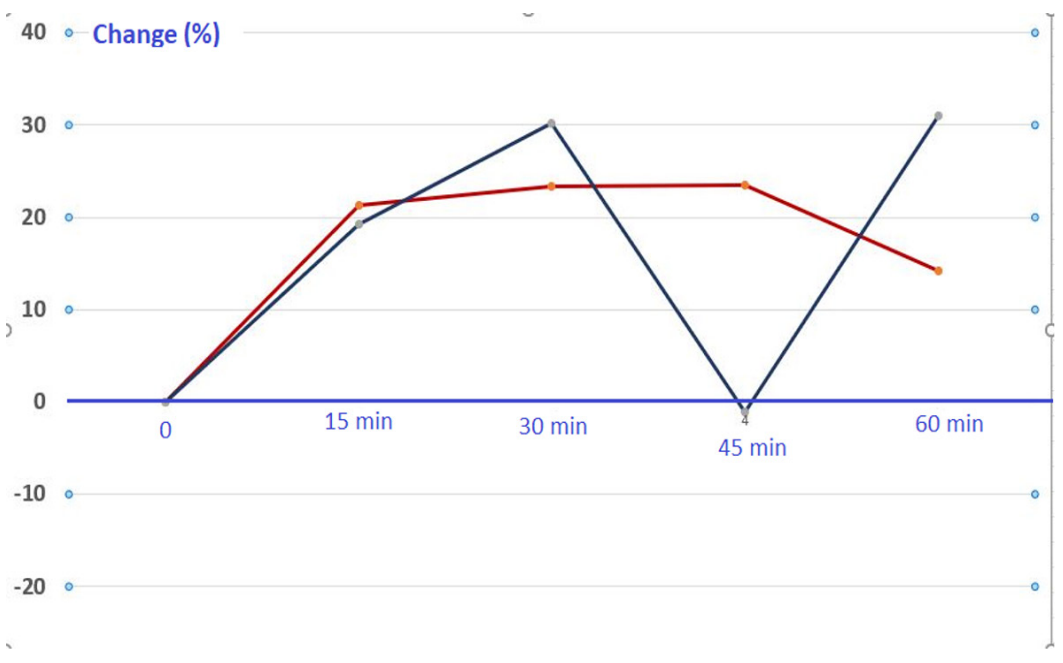

Figure 1: Alterations of lactic acid production in L. acidophilus (red) and L. casei (green) exposed to $2.4 \mathrm{GHz}$ Wi-Fi radiofrequency radiation for $15,30,45$ and $60 \mathrm{~min}$. The magnitudes of the changes compared to those of the sham (\%) are shown in this figure. 
tes cerevisiae, changing exposure frequency between 41.8 to $42.0 \mathrm{GHz}$ caused increased or suppressed growth by $15 \%$ and $29 \%$, respectively [14]. The reason behind declined cell viability after MW radiation was addressed in many studies. Growth limitation effects of RFEMF have been mostly linked to changes in enzymatic activity and DNA damage caused by an increased level of reactive oxygen species (ROS) $[15,16]$. Moreover, Vrhovac et al., have stated that colony growth reduction after exposure to $905 \mathrm{MHz}$ RF-EMF generated by Global System for Mobile Communication (GSM) pulses (at a SAR of $0.12 \mathrm{~W} / \mathrm{kg}$ ) at least in a part was due to the impairment of DNA repairing mechanisms [9]. On the other hand, the exact mechanisms which RF-EMF stimulatestheproliferation of microorganisms are notfully known, yet. It has been suggested that microwaves radiation increase life forms accessibility to energy sources like glucose by enhancing membrane permeability [17]. Another possible mechanism may be the effect of microwave radiation on the reduction of activity and expression of certain proteins involved in the apoptosis $[18,19]$.

Our results showed that RF radiation increased lactic acid production in both strains. This was independent of an increase in growth rate which was confirmed by ANCOVA test. Lin et al., stated similar results when L. rhamnosus strains were exposed to microwave radiation $(2450 \mathrm{MHz})$ for $3 \mathrm{~min}$, in some strains lactic acid production was amplified even after 9 generations [20]. Based on polymorphism analysis, it has been suggested that mutation in malate/lactate dehydrogenase and pyruvate kinase genes were the possible causes of the elevated lactic acid production.

We have previously investigated the effects of exposure to RF-EMFs of Wi-Fi routers on the sensitivity of different bacteria to widely used antibiotics. The results of our current study confirm the findings obtained in our previous study which showed that exposure to RF-EMFs only between a specific upper and lower level of irradiation (what is usually called an "exposure window") affects microorganisms [21]. A similar pattern was also reported by Carta and Desogus previously [22].

Altogether these findings may help scientists accelerate the proliferation of some probiotic bacteria and lactic acid production by shortterm exposure of RF-EMF. These results open new horizons to health and food industries to manipulate manufacturing processes time, increase production efficiency and profit margin. However, further experiments are still necessary to determine the optimum frequency, exposure time and power. Moreover, the effect of these exposure levels on the growth of pathogenic bacteria should be evaluated.

\section{Conclusion}

In this study we investigated the biological effects of the exposure of $L$. acidophilus and $L$. casei probiotic bacteria to $2.4 \mathrm{GHz}$ RF-EMF generated by a commercial Wi-Fi router on the proliferation and lactic acid production of these probiotic bacteria. Altogether our findings showed that these short-term exposures increase the proliferation and lactic acid production of L. acidophilus and L. casei probiotic bacteria. Considering the promising findings of our study, more research in this challenging area can expand the borders of our knowledge about probiotics and its growing applications in food industry.

\section{Acknowledgment}

This study was financially supported by a grant from the vice-chancellor of research, SUMS (Project No. 94-9659). The authors are thankful to Dr. SB Hashemi for his support.

\section{Conflict of Interest}

None

\section{References}

1. FAO/WHO. Health and Nutrition Properties of Probiotics in Food including Powder Milk with Live Lactic Acid Bacteria. Evaluation of Health and Nutritional Properties of Probiotics in Food including Powder 
Amanat S., Mazloomi S, M., Asadimehr H. et al

Milk with Live Lactic Acid Bacteria; Córdoba, Argentina: FAO/WHO; 2001. p. 1-4.

2. Iqbal MZ, Qadir MI, Hussain T, Janbaz KH, Khan $\mathrm{YH}$, Ahmad B. Probiotics and their beneficial effects against various diseases. Pak J Pharm Sci. 2014;27(2):405-415. PubMed PMID: 24577933.

3. Baroutkoub A, Mehdi RZ, Beglarian R, Hassan J, Zahra S, Mohammad MS. Effects of probiotic yoghurt consumption on the serum cholesterol levels in hypercholestromic cases in Shiraz, Southern Iran. Sci Res Essays. 2010;5(16):2206-9.

4. Mohammadi Sartang M, Mazloomi SM, Tanideh N, Rezaian Zadeh A. The effects of probiotic soymilk fortified with omega-3 on blood glucose, lipid profile, haematological and oxidative stress, and inflammatory parameters in streptozotocin nicotinamideinduced diabetic rats. J Diabetes Res. 2015. doi: 10.1155/2015/696372. PubMed PMID: 26347893. PubMed PMCID: PMC4548139.

5. Kechagia M, Basoulis D, Konstantopoulou S, Dimitriadi D, Gyftopoulou K, Skarmoutsou N, et al. Health benefits of probiotics: a review. ISRN Nutrition. 2013. doi: 10.5402/2013/481651. PubMed PMID: 24959545. PubMed PMCID: PMC4045285.

6. Dholiya K, Patel D, Kothari V. Effect of low power microwave on microbial growth, enzyme activity, and aflatoxin production. Res in Biotech. 2012;3(4):28-34.

7. Kushwah P, Mishra T, Kothar V. Effect of Microwave Radiation on Growth, Enzyme Activity (Amylase and Pectinase), and/or Exopolysaccharide Production in Bacillus subtilis, Streptococcus mutans, Xanthomonas campestris and Pectobacterium carotovora. Int J Microbiol Res. 2013:645-653. doi: 10.9734/BMRJ/2013/5036.

8. Grundler W, Keilmann F, Putterlik V, Strube D. Resonant-like dependence of yeast growth rate on microwave frequencies. $\mathrm{Br} J$ Cancer. 1982;5:206. PubMed PMID: 7039651. PubMed PMCID: PMC2149285.

9. Vrhovac I, Hrascan R, Franekic J. Effect of 905 $\mathrm{MHz}$ microwave radiation on colony growth of the yeast Saccharomyces cerevisiae strains FF18733, FF1481 and D7. Radiol Oncol. 2010;44(2):131-4. doi: 10.2478/v10019-010-0019-7. PubMed PMID: 22933904. PubMed PMCID: PMC3423682.

10. Taylor KA. A simple colorimetric assay for muramic acid and lactic acid. Appl Biochem Biotechnol. 1996;56(1):49-58. doi: 10.1007/BF02787869.

11. Raval S, Chaudhari V, Gosai H, Kothari V. Effect of low power microwave radiation on pigment production in bacteria. Microbiol Res. 2014;5(1). doi: 10.4081/mr.2014.5511.

12. Fang Y, Hu J, Xiong S, Zhao S. Effect of low-dose microwave radiation on Aspergillus parasiticus. Food Control. 2011;22(7):1078-84. doi: 10.1016/j. foodcont.2011.01.004.

13. Kang $Y$, Kato $S$. Thermal and non-thermal germicidal effects of microwave radiation on microbial agents. Indoor Built Environ. 2014;23(8):1080-91. doi: $10.1177 / 1420326 \times 13490180$.

14. Grundler W, Keilmann F, Fröhlich H. Resonant growth rate response of yeast cells irradiated by weak microwaves. Phys lett A. 1977;62(6):463-6. doi: 10.1016/0375-9601(77)90696-X.

15. Ahmed LT, Majeed AD, Shaima'a AS. The effect of mobile waves on the growth of pathogenic fungi. Int J Curr Microbiol Appl Sci. 2015;4:838-842.

16. Diem E, Schwarz C, Adlkofer F, Jahn 0, Rüdiger $H$. Non-thermal DNA breakage by mobile-phone radiation $(1800 \mathrm{MHz})$ in human fibroblasts and in transformed GFSH-R17 rat granulosa cells in vitro. MRGTEM. 2005;583(2):178-83. doi: 10.1016/j. mrgentox.2005.03.006. PubMed PMID: 15869902.

17. Shamis $Y$, Taube A, Mitik-Dineva N, Croft R, Crawford RJ, Ivanova EP. Specific electromagnetic effects of microwave radiation on Escherichia coli. Appl Environ Microbiol. 2011;77(9):3017-22. doi: 10.1128/AEM.01899-10. PubMed PMID: 21378041. PubMed PMCID: PMC3126418.

18. Cohen I, Cahan R, Shani G, Cohen E, Abramovich A. Effect of $99 \mathrm{GHz}$ continuous millimeter wave electro-magnetic radiation on $\mathrm{E}$. coli viability and metabolic activity. Int J Radiat Biol. 2010;86(5):390-9. doi: 10.3109/09553000903567912. PubMed PMID: 20397844.

19. Calabrò E, Condello S, Currò M, Ferlazzo N, et al. Modulation of heat shock protein response in SH-SY5Y by mobile phone microwaves. World $J$ Biol Chem. 2012;3(2):34-40. doi: 10.4331/wjbc. v3.i2.34. PubMed PMID: 22371824. PubMed PMCID: PMC3286792.

20. Lin H, Chen X, Yu L, Xu W, Wang P, Zhang X, et al. Screening of Lactobacillus rhamnosus strains mutated by microwave irradiation for increased lactic acid production. Afr J Microbiol Res. 2012;6(31):605565. doi: 10.5897/AJMR12.434.

21. Taheri M, Mortazavi SMJ, Moradi M, Mansouri S, Nouri F, et al. Klebsiella pneumonia, a Microorganism that Approves the Non-linear Responses to Antibiotics and Window Theory after Exposure to Wi-Fi $2.4 \mathrm{GHz}$ Electromagnetic Radiofrequency Radiation. J Biomed Phys Eng. 2015;5(3):115. PubMed PMID: 26396967. PubMed PMCID: PMC4576872.

22. Carta R, Desogus F. Possible non-thermal microwave effects on the growth rate of pseudomonas aeruginosa and staphylococcus aureus. Int Rev Chem Eng. 2012;4(4):392-8. 